Int. J. Electrochem. Sci., 14 (2019) $8141-8160$

International Journal of

ELECTROCHEMICAL

SCIENCE

www.electrochemsci.org

\title{
Electrocatalytic Oxidation of Methanol on NiMnsalpnY Modified Glassy Carbon Electrode
}

\author{
Xia Hua ${ }^{1}$, Zhihong Gao ${ }^{1}$, Yan Wang ${ }^{1, *}$, Wenyang Wang ${ }^{1}$, Baocheng Wang ${ }^{2}$, Ruifeng Li $^{1, *}$ \\ ${ }^{1}$ College of Chemistry and Chemical Engineering, Taiyuan University of Technology, Shanxi, \\ 030024, China \\ ${ }^{2}$ College of Materials Science and Engineering, Taiyuan University of Technology, Shanxi, 030024, \\ China \\ *E-mail: wangyan@tyut.edu.cn, rfli@tyut.edu.cn
}

doi: $10.20964 / 2019.08 .55$

Received: 28 February 2019/ Accepted: 26 April 2019 / Published: 30 June 2019

\begin{abstract}
Zeolite composite catalyst NiMnsalpnY prepared by the flexible ligand method is examined for its redox process and electrocatalytic activities towards the oxidation of methanol. The methods of cyclic voltammetry (CV), chronoamperometry (CA), chronocoulometry (CC) and electrochemical impedance spectroscopy (EIS) are employed. The NiMnsalpnY composite system presents the characteristic of quasi-reversibility, which can be anticipated for the $\mathrm{Ni}(\mathrm{III}) / \mathrm{Ni}$ (II) couple. In the presence of methanol, the NiMnsalpnY modified electrode, compared with other modified electrodes, reveals a significantly higher response for the electrooxidation of methanol. The addition of a small amount of alloying element $\mathrm{Mn}$ to pure Ni can greatly enhance the ability of methanol electrooxidation. The anodic peak currents corresponding to methanol oxidation exhibit a linear dependency on the square root of the scan rate, indicating a diffusion controlled process. The electrocatalytic peak currents are proportional to the concentration of methanol, suggesting that the electrocatalytic oxidation of methanol at NiMnsalpnY/GC electrode seems to be certain. The mechanism of electrocatalytic methanol oxidation based on the electrochemical cyclic regeneration of $\mathrm{Ni}(\mathrm{III}) \mathrm{Mn}$ (III) active sites and their redox reaction with methanol in subsequent process is discussed. The kinetic parameters such as the electron transfer coefficient $\alpha$ (the value is 0.34 ) of the electrode reaction, the diffusion coefficient $D$ (the value is $1.28 \times 10^{-8} \mathrm{~cm}^{2} \cdot \mathrm{s}^{-1}$ ) of methanol and the catalytic rate constant $k_{\mathrm{cat}}\left(\right.$ the value is $1.55 \times 10^{4} \mathrm{~cm}^{3} \cdot \mathrm{mol}^{-1} \cdot \mathrm{s}^{-1}$ for the concentration of $0.5 \mathrm{M}$ methanol) have been derived. The resistance of the electrocatalytic oxidation system has been investigated through the EIS regime.
\end{abstract}

Keywords: Zeolite, NiMnsalpnY, Methanol Electrooxidation, Zeolite Composite, Fuel Cell 
(C) 2019 The Authors. Published by ESG (www.electrochemsci.org). This article is an open access article distributed under the terms and conditions of the Creative Commons Attribution license (http://creativecommons.org/licenses/by/4.0/). 